\title{
Assessment of Financial Literacy Formation Methods in Mathematics Education: Financial Computation
}

\author{
https://doi.org/10.3991/ijet.v15i16.14587
}

\author{
Alma Abylkassymova \\ Abai Kazakh National Pedagogical University, Almaty, Kazakhstan \\ Akhan Mubarakov \\ L.N. Gumilyov Eurasian National University, Nur-Sultan, Kazakhstan \\ Zhazira Yerkisheva ${ }^{(凶)}$, Zhannur Turganbayeva \\ Khoja Akhmet Yassawi International Kazakh-Turkish University, \\ Turkestan, Kazakhstan \\ zhazira.erkisheva@ayu.edu.kz \\ Zhomart Baysalov \\ Kyrgyz State University I. Arabaev, Bishkek, Kirghizstan
}

\begin{abstract}
Learning the basics of financial computation to improve financial literacy of students in school mathematics is not enough to deepen modern economic knowledge and its correct application in life practice, which requires a more comprehensive view of the process of teaching mathematics. The purpose of the research - to prepare a teaching guide during the process of studying mathematics in high school on the formation of financial literacy skills. Research methods - expertise and pedagogical experiment, theoretical, methodical and mathematical analysis of educational and methodical complexes and manuals, textbooks used in schools of the country, scientific and theoretical problems, philosophical, psychological and pedagogical, methodical and mathematical literature aimed at teaching the basics of financial literacy in mathematics classes. Results - methods of teaching the basics of financial statements in mathematics lessons in high school will increase not only students' knowledge of mathematics, but also the level of knowledge about financial calculations and their interest in learning and their ability to read, the quality of knowledge acquisition and their ability to increase their financial literacy. The results of the study can be used to train future mathematics teachers in secondary schools and higher education institutions, to improve the teaching content and methodology of mathematics, and to improve the professional development of teachers.
\end{abstract}

Keywords-Financial computing, financial literacy, mathematical literacy, learning system, differentiated learning, interactive method, problem learning. 


\section{Introduction}

\subsection{Relevance of the study}

Financial literacy is the main tool against poverty, one of the ways to reduce economic risks in the country [1].

Financial literacy as an economic category is currently an object of study for domestic and foreign researchers. The urgency of the problem of improving financial literacy has led to the fact that in modern scientific literature there are different definitions of this concept [2-5]. In analyzing the content of the concept and the different approaches to its definition, we conclude that, in the broadest sense, financial literacy can be defined as the ability to use financial knowledge and skills to make informed decisions and take effective action on financial resources to ensure one's own wellbeing and financial security.

Much attention is paid to recent research and development aimed at improving financial literacy to prevent financial illiteracy [6-7].

It should be noted that financial literacy can be formed not only when studying the course of economics, the basics of financial analysis in the process of pre-profile and professional training of students, but also on the basis of a separate set of subjects studied in a secondary school. It should be noted that in this case, mathematics has a special role to play, as it provides the basic apparatus for describing, modeling and forecasting various phenomena in economics and finance [8].

A.Lusardi noted in his article that in the modern world financial literacy should be considered as important as basic literacy, without it people and societies cannot fully develop their potential [9].

The authors [10] in their research aimed to determine the presence of a basic structure that explains the knowledge on the topics of income, money management, savings and investments, expenses and loans for students of higher education institutions.

Kazakhstan's education system, through the creation of a new education system in the Republic, has embarked on a course of introduction to international standards of education. This, in turn, is associated with significant changes in the theory of pedagogy and educational process, in particular, the paradigm of education has changed, the content of the educational process has been updated, a new view has appeared, and new relationships have emerged.

In order to introduce the world standards of education, Kazakhstan participates in the International PISA research, where the results of the obtained knowledge of 15year-old students are evaluated in three directions: "Natural literacy", "Mathematical literacy" and "Educational literacy".

The tasks of this study are aimed at the application of knowledge obtained in secondary school in everyday life, in particular, for the correct analysis of problems with different ways of solving them in a logical form, making the right decisions, it will help the younger generation to find the right way out of various situations encountered in life. 


\subsection{Literature review}

A special edition of HsiaoChing, She and others entitled "Science and Mathematics Literacy" states that in order to improve learning in schools, a PISA programme has been developed, the composition and results of which, beyond official calculations, are helping the process of teaching mathematics to students, while at the same time improving the education system of the world and individual countries [11].

According to research by the Organisation for Economic Co-operation and Development (OECD), PISA is the basis for assessing mathematical literacy. Today's world uses mathematical knowledge to correctly solve problems in everyday life and to determine its practical, applied direction, on the basis of which it is possible to form attitudes to learning and studying mathematics [12].

One of the modern requirements to the results of the knowledge acquired by students is to skillfully set important responsibilities for them in adult life and to master the knowledge gained so that they can make the right decisions. In the process of studying various sections of mathematics, the student must understand why he or she will need this subject, how the concepts studied are related to important problems of practical activity.

One of the most important problems in the education system is the resolution of the contradictions between theory and practice in the course of improving the quality of knowledge acquired by students [13].

Mathematical literacy is the use of mathematics and extracurricular activities in the subject in everyday practice, in the study of specific problems and in finding solutions to them [14].

Many scientists have been involved in practical and applied mathematics applications. These scientists considered the use of mathematical apparatus, the addition of teaching methods and the content of school mathematics courses to practical tasks in order to solve problems related to strengthening the applied field of mathematical knowledge, mainly, to solve problems arising in each branch of science and applied in different spheres of human activity [15-17].

Solving practical problems in mathematics lessons in primary school helps to build financial literacy among students. In his opinion, the sooner students are taught financial knowledge, the sooner they will make the right financial decisions related to their own financial resources.

Therefore, in order to develop students' mathematical literacy by teaching applied mathematics and linking its practical orientation to everyday real life, we need to broaden students' horizons.

Mathematics is the most popular course that is considered to implement financial education goals, probably due to the established positive association and theoretical connectedness between financial literacy and mathematical skills[18-19].

The subject of mathematics is undoubtedly a link between financial and mathematical literacy and practical problems in real life [20].

As noted above, mathematics has great potential in organizing a learning process focused on improving financial literacy among students. These opportunities can be realized in two directions: first, by expanding the content of educational material in 
the basic training of students, and second, by organizing additional classes aimed at solving the problem. The first of these directions can be realized through the inclusion of small sections (paragraphs) in the courses, which demonstrate the application of the mathematical apparatus in the economy. Such sections will allow students to see the relationship between economics and mathematics, as well as to expand their financial and economic knowledge. The second direction is related to the creation of elective courses in mathematics, which demonstrate the applied capabilities of mathematics in solving financial and economic problems. Such courses are aimed, on the one hand, at realization of the basic task of formation of financial literacy of students, on the other hand, at expansion and deepening of knowledge of students on separate sections of mathematics.

The analysis of scientific sources on the studied topic shows that the field of financial computing is one of the main areas of applied mathematics. Fundamentals of financial calculation of the conditions for their implementation in mathematics at school fully comply with modern requirements. The technology of teaching the basics of financial computing was first developed in high school in mathematics.

The development of the design of the multi-level content of the course on the basics of financial computing in the context of professional education for high school students is based on the following: a) the demand and, at the same time, the differentiation in the interests, needs and capabilities of students of different profiles for the development of elements of financial computing; b) the need to saturate the content of specialized mathematics education for high school students with elements of financial calculations related to various payments, taxes, lending, insurance and other financial transactions, since in modern conditions the financial and economic literacy of every person becomes one of his competency-based characteristics, as in everyday life, directed on the formation and development in students of ways of independent activity in mastering the content of mathematics applications in areas of financial computing.

The basics of financial computing in the context of specialized education for high school students in mathematics consists of three stages while designing the multilevel content of the course: preparatory, construction and evaluation. At the preparatory stage, the preferences of students of different profiles to issues related to the field of financial computing are studied, the principles of selecting the content of tasks for financial computing are determined, methods, organization and training methods are selected to implement a personal-activity approach. At the design stage, a multi-level content is structured courses on increasing difficulty levels of elective, elective, or special courses which were focused on the cognitive interest of high school students in the field of financial accounting. At the assessment stage, it is expressed in reflective activity related to the analysis, examination and correction of the design process of the multi-level content of the introductory course in financial mathematics at the senior level of general education. 


\section{Materials and Methods}

\subsection{Research methods and steps}

The study developed the target, substantive and procedural components of the methodology for specialized mathematics education in the context of the implementation of the multilevel content of its applications in the field of financial computing.

Active forms were used on the forms of organizing the multi-level content of the course "Fundamentals of Financial Computing" in senior classes of educational institutions, i.e. "teaching methods, when using in which the educational activity is creative, cognitive interest and creative thinking are formed" These include, in particular, such as project methods, problem, game, heuristic, modular, critical situations, etc. [21].

Graded learning methods were used to achieve a consistent assessment of learning goals across levels of convenient learning that organizes student interest and motivation. Differentiated teaching is one way of optimizing the learning process and eliminating gaps in knowledge [22]. Differentiated learning is the presentation of tasks for students at several levels and the assessment of their learning outcomes. In the formation of students' financial literacy through teaching the basics of financial calculus, the Bloom taxonomy was used in each lesson.

Experimental work to evaluate the effectiveness of specialized mathematics teaching methods in the implementation of multilevel contents of applied mathematics in the field of financial accounting, the Daryn School of N.Ondasynov in Turkestan, Turkestan Region, schools №15, №23 inTurkestan, Kentau for gifted children. Daryn School was acquired. The main purpose of the experiment definition phase was to investigate and analyze the pedagogical experience of developing senior students' practical skills in financial accounting.

We conducted a survey to determine the expression of interest (life, professional, educational) of the students who decided to continue their education at the upper secondary. The diagnostics show that there is a differentiation between the interests and the needs of students in financial, credit and insurance transactions. But overall, the survey points to the fact that the course, in which we apply mathematics in the field of financial accounting, is very relevant, important, and always in demand among the majority of students. Thus, the personal (designer) and social (students and their parents) needs of the introductory course of financial accounting are the same and require the design of upper secondary school students.

\subsection{Experimental base and study participants}

At the beginning of the experiment, in 2016/2017 academic year, diagnostic work was carried out, which included tasks of financial and economic content. The results of its implementation by 192 students were used to identify the initial level of skills of high school students in the field of practical applications of school mathematics course related to financial calculations. In carrying out the control work, pupils could 
receive a maximum of 12 points (the 1 st task was assessed as 2 points, the 2 nd and 3 rd tasks as 3 points, and the 4th task as 4 points). If a solution algorithm was correctly composed in the task, but a computational error was made, the grade was reduced by 1 point.

\section{Results}

\subsection{Structure and content of the course "Fundamentals of Financial Computing".}

Financial relations in modern society permeate all spheres of human activity. The ability to intelligently conduct analysis, compare various financial situations, calculate income and loss in a certain situation is necessary for today every modern person.

In conditions of profile training it assumes saturation of the content of a school mathematics course with its applications arising in various spheres of human activity, taking into account specificity of developed profile directions, and also interests, aptitudes and possibilities of pupils that allows to solve problems of individualization of educational process to a fuller extent[23].

The target component of a technique of profile training of mathematics in the conditions of realizable level content of an introductory course of financial calculations in profile training is characterized by target installation of deepening and expansion at pupils of different profiles of representations about applied value of mathematics in sphere of financial relations, the differentiated content on increasing levels of complexity A, B and C.

In this regard, the "Fundamentals of Financial Computing" course sets objectives for each level.

\section{At level A:}

- Educational: formation of ideas on the application of theoretical knowledge in mathematics in the study of new concepts related to economic problems of a certain type, mastering the methods of financial calculations and application of the acquired knowledge in everyday life;

- Developing: improving the level of computing skills and algorithmic culture, development of verbal and logical thinking, creative, educational and research abilities at the level necessary in everyday life;

- Educational: development of social traits of the student's individuality, education of an active life position, self-confidence, personal attitude to the material under study through acquaintance with the fields of activity of society in which financial computations are used.

\section{At level B:}

- Educational: formation of ideas on the application of theoretical knowledge in mathematics in the study of new concepts related to the economic problems of a certain type, mastering the basics of financial calculations for the application of the 
received knowledge in everyday life and continuing further education related to the economic content;

- Developing: raising the level of computing skills and algorithmic culture, development of verbal and logical thinking, creative, research abilities at the level necessary in professional activity connected with economic specialties;

- Educational: development of social traits of the student's individuality, cultivating an active life position, self-confidence through tasks of financial content, understanding the importance of mathematical knowledge in the activity of a specialist with economic education.

\section{At level C:}

- Educational: formation of ideas about the means of modeling economic processes related to financial operations, mastering mathematical knowledge and skills in the analysis and study of financial situations;

- Development: improving the level of computer skills and algorithmic culture, development of verbal and logical thinking, creative, research and development abilities at the level necessary for continuing education in the chosen profile direction;

- Educational: development of social traits of the student's individuality, education of active life position, self-confidence, development of interest in mathematics through the application of theoretical knowledge, interpretation of their practical significance in financial, credit and insurance operations.

The content component is characterized by differentiation of the content of the course "Fundamentals of Financial Computing" by increasing levels of complexity.

At the design stage the multilevel content of the course is structured by increasing levels of complexity.

Level $\mathbf{A}$ is focused on obtaining knowledge and skills to use them in life activities and is designed for students who want to satisfy their cognitive interests in the subject area in question. The content line of the course - overview (introductory), form of training - optional course.

Level B is oriented to gaining knowledge and skills to use in practice, to study the subject area in higher education institutions. Its content is related to strengthening the economic component of the course, while the form of study is an elective course.

Level $\mathbf{C}$ is oriented to obtaining knowledge and skills for direct use in professional activity and successful study of related disciplines of specialization in higher education institutions. The content of the course is related to strengthening the mathematical component of the course, while the form of study is a special course.

Presence of transitional levels A-B and B-C is caused by necessity of creation of conditions for realization of needs and possibilities of separate categories of students in the course of studying the given course. Thus, all categories of students studying at the senior level of general education will have the opportunity to get equal access to the study of financial mathematics, and in accordance with their capabilities, aptitudes and needs.

All of this is directly related to the issue addressed in the course "Fundamentals of Financial Computing", a practical guide for teaching students to resolve issues related 
to financial management in specific life situations. In this course, students learn about the different types and types of interest, methods of calculating credit transactions, with the financial world, with the assessment of accrued amounts from inflation accounting and interest-bearing tax for a given period, get an initial concept related to such an important social issue.

The content of this course can be varied taking into account the aptitudes, interests and level of readiness of students, which makes it possible to use it to introduce an optional course in general education classes, elective courses in profile classes, special courses in natural and mathematical classes.

The course is designed for students in grades 10-11 of general education institutions. The scope of the course depends on the level of its study and is designed for an elective course - 34 hours, for elective courses - 68 hours, special courses - 02 hours. $I$

The methodological goals of the course "Fundamentals of Financial Computation" are to develop interest in the subject, intellect, logic of thinking; to expand students' knowledge in economics and mathematics; to form initial skills of solving life situations of economic character; to show the need for mathematics as an academic discipline; to help students to decide on future career choice, hanging mathematical, computer and financial literacy.

In the course of our theoretical analysis and practical testing of the possibilities of multi-level content of the course "Fundamentals of Financial Computing" in high schools of general education institutions it was found that the dominant methods of teaching in these conditions are active methods, i.e. methods of teaching, in the use of which the educational activity is creative, formed cognitive interest and creative thinking.

The model of interactive learning includes modeling of life situations, use of roleplaying games, joint problem solving. In the process of learning, limits the specificity of any participant or idea (in particular, paying attention only to successful students). It teaches humanity and a democratic approach to this model.

\subsection{Methods of forming financial literacy by studying the course of basics of financial calculations}

The importance of interactive methods is very high in the formation of creative actions that increase the interest of students in the lessons.

At the same time, by means of training students in specialized subjects, preparation for the choice of a future profession is carried out, passing of financial calculations on a school mathematics course will not only help students to master the theory, but also will give the chance to gain valuable experience at their application in practice. This, in turn, is a natural reason for expanding the use of mathematical knowledge to solve financial problems in practice and in real life.

One of the necessary conditions for implementing the principles of training is to provide motivation for all training activities. This will help students to master the skills of the future profession and will show the important need for new lessons for the implementation of their own future. 
Motivation is necessary for teachers of mathematics both to know the subject matter of mathematics in general and to form their methodological views, because, in addition to providing students with quality knowledge, teachers must manage the learning process [24-25]. To do this, teachers need to know how to motivate students. Therefore, before introducing new terms, teachers need to explain the nature of education in these terms, $b \quad$ ased on numerous case studies.

Case studies are innovative learning methods that use facts, evidence, real-life information from a briefcase, cassette, and stand to provide a specific professional solution to a problem that they discuss and solve.

Case-stage: by examining the situation described, students identify the problem, small groups present concrete ways of solving it, and each group comes to its own solution through discussion and exchange of opinions. The groups, in the presence of the teacher, will try to prove the correctness of their own solution to the problem. It is not necessary to come to one common solution at the end of the discussion.

Planning is the initial preparatory step to achieve a specific goal. If educational planning is the definition of a goal and the ways to achieve it, then the educational methods are the measures taken to overcome the emerging problems on the way to the goal.

Planning is carried out by solving five main problems. This: What is the science? When will I learn? For what purpose will I learn? How will I learn? Where will I learn?

At present, the main goal of the education system is to train a specialist who is ready to compete. School is a learning environment, and the heart is the teacher. The peculiarity of a researcher's creative activity is that his or her lessons are diverse in nature and reach the heart of the individual.

Using the above methods in the course of training in the basics of financial calculations can be formed in the students financial literacy.

On the basis of the Case Study method, students were given problem problems and the necessary solutions were found.

Task 1 - case study: Zharas, who has not reached the age of 18, is still a student himself. He is the only guy who has a regular mobile phone between his friends. Competing with friends, says that in the near future there will be a mobile phone Iphone 11, 64 GB. However, there are 5 children in his family and their presence is a student. The mother's salary is 50,000 tenge. The salary of parents is 70,000 tenge. Payment for utilities is made monthly for 25,000 tenge. Every day 3000 tenge is spent on the saved funds of the whole family. The cost of a mobile phone brand "Iphone11", $64 \mathrm{~GB}$ is 384000 tenge.

Nurtas demanded to move his mother to retail outlets and buy this phone. His mother does not have money for such thing, and the store clerks warned that they can take a mobile phone on credit and pay it in installments. "KASPI BANK" will provide installments for 24 months, "HOME Credit Bank" - 12 months, "Eurasia Bank" - 18 months. Despite the fact that the mother said that the child does not have enough monthly funds to support one family, Nurtas did not change his decision. How can you resolve this issue?

At level A- What would you be able to meet the requirements? 
At level B- Do you think which of the banks offered by the store sellers is profitable to get a loan? Have you applied for a consumer loan to meet Nurtas ' requirements?

To level C - Do you also support the requirements of a student? What actions can you take when you are in his mother's place? What type of loan do you choose to get your child's attention? For how many years you can get 384,000 tenge with a monthly payment of 7500 tenge.

By solving these life problems, students not only learn them, but also analyze them according to their educational meaning, awaken their critical thinking and positive attitude to life, contribute to solving life problems, and improve financial literacy.

Discussion is a way to accelerate decision making in the course of group work, a method to increase the benefit and intensity of the lesson, which activates the actions of the student together with the class, the process of joint search for a solution to the problem, discussion and reasoned decision-making.

In financial computing lessons in the school's math course, students can be asked to personally understand the meaning of terms used in everyday life.

For example:

How do you explain the meaning of the word percentage in life practice?

What is your attitude towards the loan and its types?

In basic financial computing lessons, using a teaching method based on such problematic lessons is useful for students in schools. Problem Lesson - This type of lesson has a good influence on the development of creativity of students. Creating one or more problem situations in the lesson and then solving them gives students confidence and develops their creativity.

The heuristic conversation method is used to search for and identify creative approaches and original solutions to problems related to both learning and practical activities. It is based on the sequence of questions asked in the process of solving the problems and reducing their problems to the level required in the current situation. Each subsequent heuristic question forms a new strategy of activity, which brings problem solving closer to the final completion. As a result, the tasks are broken down into subtasks. The main rule is that the teacher does not report the ready knowledge, but the posed questions lead pupils to new conclusions, rules, relying only on their knowledge, stock of ideas, as well as personal life experience. The purpose of this method is to teach students to build heuristic questions on their own, which would simplify the task and allow them to get the right answer by using self-monitoring techniques. When considering pawnshop and consumer credit issues, tasks such as the following are used.

Task 2: The entrepreneur did not have enough money to open a new store.

KZT 300,000 and he applied to the bank for a lombard loan for 2 months. The bank offers the following conditions: assessment of the value of collateral in the amount of $70 \%$, for each day is charged $0.6 \%$, service of the loan - 1250 tenge. Determine the value of the collateral to be provided by the entrepreneur to the bank to open the loan. Estimated date of credit opening is 15 October. Interest is charged immediately. 
The backbone of the task may be supplemented by questions that both the teacher and students are entitled to ask. In the situation in question, for example, the following questions may be asked:

At level A - if you were an entrepreneur, would you use a pawnshop loan or would you choose another type of loan in this case?

At level B - if you were a banker, what kind of credit would you choose?

could you recommend an entrepreneur and why?

At level C - if this amount is taken on the terms of a consumer loan, namely: the term of the loan is 6 months, at $19 \%$ per annum, the repayment plan is made according to the method 《account from hundred》, then which of the loans is more beneficial to the consumer; for how long does it take to take a loan to make a lombard loan more profitable?

Task 3: Mr. Nurtas intends to buy with a mortgage loan a one-room flat worth 30 Ltd. According to the terms of the contract, for the option he is interested in, the down payment is 10,000 USD, and then at the end of the first month and for 7.5 years he will have to pay 350 USD monthly. The applicant is concerned about whether these payments correspond to the mortgage rate of $12 \%$.

At level A- In your assessment, aren't they overstated?

At level B-A, what do you think?

At level C - If you wanted to buy a one-room apartment?

Would you choose a mortgage loan or receive money as a depositor in the bank?

With this approach, students learn to model and solve problem situations on their own, taking advantage of their knowledge of financial mathematics.

\subsection{Experimental testing of the effectiveness of teaching the basics of financial computation in a school mathematics course}

Level, differentiated, educational criteria have had a positive impact on increasing the interest of students in the subject under study, in choosing a future profession and in finding solutions to financial problems encountered in life.

Pedagogical mastery is not a result of talent, but a result of learning and search.

Bloom's taxonomy was applied at each lesson in forming financial literacy of students by means of teaching the basics of financial calculations. Bloom taxonomy, a large number of ways, methods and strategies not only helps students to assimilate the lessons well, but also certainly has a strong impact on the development of creative abilities, freedom of thought, the mastery of bringing their thoughts to the listener, in general, on the formation of an integral personality.

Bloom's taxonomy is formed from the following stages of "knowledge, understanding, use, analysis, collection, evaluation". For each of these six stages, different strategies of STB technology are used. At the stage of "knowledge" of Bloom's taxonomy, using a certain method, one remembers, preserves, and reflects on previously obtained knowledge. For example, when arousing interest, they use the challenge of thinking processes, grouping, similarities and differences, etc., to learn the meaning of GIGO-I, GIGO-II, self-study, paired learning, exchange of ideas, drawing conclusions, posing questions, repetitive questions, etc., when thinking about the Venn dia- 
gram, correspondence schedule, five-line verses, essays, discussions, worldview, etc. In the "understanding" stage, to determine the understanding of new knowledge, to establish dialogues, to reveal the basics of the topic through the task of preparing a forecast. In the third stage, "application" uses meanings such as the application of the knowledge gained, problem solving, e.g. "find my mistake", "make a sentence on the topic", "compare", etc. At the stage of "analysis", comparison by "cubism" in group discussion, research, provides direction for determining the main idea of the topic under discussion. The fifth stage of the "collection" of disparate definitions brings together a single whole. The "assessment" stage determines the need for this material, exchanges ideas and evaluates each other. Thanks to this strategy, the way of speaking, the skill of the word, and the ability to express one's thoughts accurately develop.

These broad opportunities, providing comprehensive support for the development of the younger generation, have an impact on the financial literacy of students.

The pedagogical experiment was conducted in the profile classes of the schoolgymnasium № 15 named after Magzhan Zhumabaev and in the school "Daryn" named after N. Ondasynov in Turkestan. The participants of the experiment were divided into control and experimental groups.

We are analyzing new technological methods used to teach the basics of financial calculations of school mathematics course, increasing mathematical literacy and activity of students at school. During the research in the stating experiment was put the study and analysis of pedagogical experience of forming practical skills of high school students and their condition in the field of financial calculations. At the same time, psychological, pedagogical and educational literature was also analyzed, as well as dissertation studies on the degree of elaboration of the problem highlighted by us. Diagnostic work with students, questionnaires and conversations with their parents and teachers were conducted. The survey of high school students' practical skills in solving the subject problems of financial and economic content offered in school practice was conducted using diagnostic works. For this purpose, students were offered to solve the relevant tasks, grouped by us in three levels of complexity. The first level included problems of financial and economic content, during the solution of which the ability to apply knowledge on a particular topic of the school mathematics course and perform simple calculations were tested, the second level - the ability to use knowledge on several topics of the school mathematics course, and the third level - the ability to independently search and select appropriate ways to solve them. As a result, of the 192 students participating in the survey, $25.45 \%$ were able to complete the tasks: level 1, 25.45\%; level 2, 13.12\%; and level 3,4.55\%, which shows a very low level of ability to solve economic and financial problems. The low results of such tasks can be partly explained by the fact that they are rarely used in the compulsory examination of algebra and began analysis in high school, and for this reason graduates pay almost no attention to them. And in the basic school as well, the results of such tasks traditionally give low indicators. The reasons for this state of affairs were revealed by taking into account the opinions of mathematics teachers, for which we conducted interviews with teachers. In the course of these conversations with teachers, the following questions were posed to teachers: 
- What should be done to improve the financial and economic literacy of students?

- Why, in your opinion, schoolchildren are poorly prepared to solve problems of an applied nature? - Indicate the reasons for the low level of high school students' decision-making skills.

As a result of the interviews, it was found that the majority of teachers (82\%) believe that the main reasons for the problems are insufficient coverage of applied materials by existing mathematics textbooks for general education institutions, economic and financial literacy students.

By the end of the search and training stage of the experiment, the layout of the multi-level content of the course "Fundamentals of Financial Computation" and its preliminary testing in the conditions of specialized training were carried out taking into account the prevailing preferences of students in the field of financial computation: at level A - in the framework of an facultative course, at level B - an elective course, at level C - a special course. Thus, between 2016 and 2019, the number of students who expressed a desire to study this course increased.

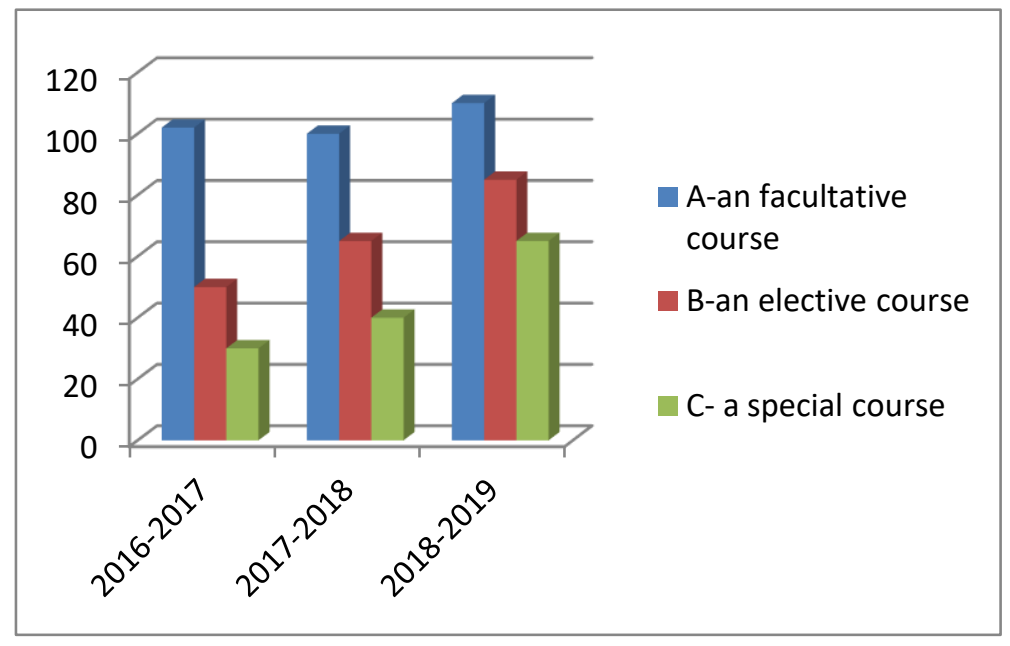

Fig. 1. Distribution of the number of students who took this course

The control group included students who studied mathematics at the basic and specialist levels, as well as multi-level students who studied the course. Comparison of the results of the control activities of the two groups, EG and CG, was carried out using the criterion (chi-square). For this method of random selection from the experimental (EG) and control (CG) groups were formed samples of 50 people, respectively. With the help of a scale was determined by the level of knowledge of students by the decision of the proposed tasks in the control work. For this purpose, four levels of knowledge $(\mathrm{L}=4)$ were identified: very low - the number of points scored was from 0 to 3 ; low - from 4 to 6 , average - from 7 to 8 ; high - from 9 to 12 . The school mark was placed according to the allocated knowledge levels, namely: $\langle 2\rangle\rangle-$ very low knowledge level, $\langle 33 \gg$ - low, $\langle 44\rangle$ - average, $\langle\langle 5 \gg$ - high. Pupils were considered to 
have coped with the tasks, if the score was $\langle\langle 4 \gg$ or $\langle<5 \gg$, i.e. 7 to 9 points were scored. As a result of the control work, a schedule of results of measuring the level of skills of pupils of the experimental and control groups in the field of practical applications of the school mathematics course related to financial calculations to the beginning of the experiment was drawn up.

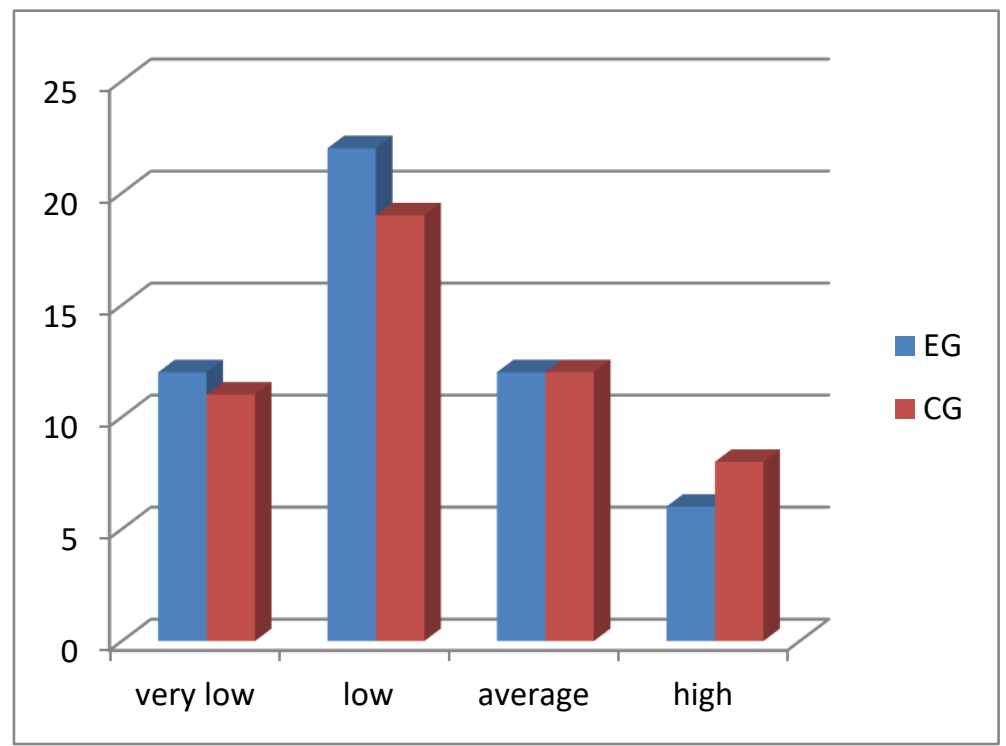

Fig. 2. Adoption of practical applications of school mathematics course related to financial computations to the beginning of the experiment

As a hypothesis which we tested, we considered a proposal: there is no difference between the initial levels of practical skills to solve the subject problems of financial and economic content before the course "Fundamentals of financial computations" in the control and experimental groups.

The condition of the null hypothesis is the requirement:

$\chi_{\text {эми }}^{2}<\chi_{1-\alpha}^{2}$ where - level of importance, equal to 0,05 . At the same time, the critical value of the criterion $\chi^{2}$ matched to the degrees of freedom we choose $\mathrm{L}-1=$ $=4-1=3$ and level of importance, equals 7,82 (Novikov, 2008). Computation of empirical value $\chi_{\text {эмп }}^{2}$ for comparable samples was conducted according to an appropriate formula: 


$$
\chi_{\text {эмn }}^{2}=N \cdot M \cdot \sum_{i}^{4} \frac{\left(\frac{n_{i}}{N}-\frac{m_{i}}{M}\right)^{2}}{n_{i}+m_{i}}
$$

where $\mathrm{N}$ is the number of students in the experimental group $(\mathrm{N}=50), \mathrm{M}-$ enrolment in the control group $(\mathrm{M}=50)$.

Because $\chi_{\text {эип }}^{2}=1,47<7,82=\chi_{0,05}^{2}$, then it should be concluded that the zero hypothesis we have put forward is being fulfilled, i.e. before the beginning of the experiment the students of the control and experimental groups have no significant differences between the initial levels of practical skills to solve the subject problems of financial and economic content. At the end of this stage of the experiment, the final control work was carried out. Based on the results of the control work, a schedule of measurements of the level of skills of these high school students in the field of practical applications of school mathematics course related to financial calculations was drawn up.

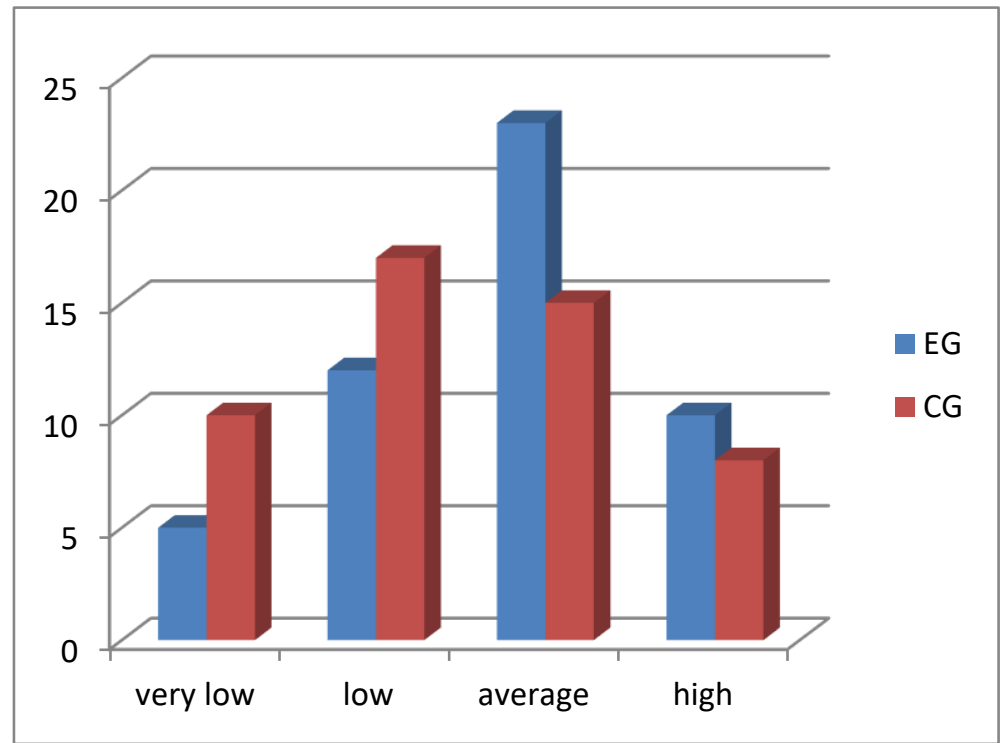

Fig. 3. Adoption of practical school mathematics applications related to financial computations by the end of the experiment

For $\chi_{\text {эми }}^{2}=13,37>11,34=\chi_{0,01}^{2}$ Comparable results of the final work in the control and experimental groups differ with $99 \%$ reliability. At the same time, during the period of the experiment, the number of high school students who successfully coped with the plot tasks of financial and economic content has increased in the ex- 
perimental group. Thus, it can be concluded that studying the course "Fundamentals of Financial Computing" at one of a certain level allows students to successfully cope with a large number of tasks provided, which significantly increases the formation of practical skills of high school students in the field of practical applications of school mathematics course related to financial calculations.

\section{Discussions}

According to the requirements of school curricula, the value of mathematical education lies in its practical application in life, in the study of related subjects, in the continuation of education, which is measured by accurate mathematical knowledge. In this regard, there is a need to show students how mathematical theory can be applied to their applications in mathematics education. In other words, in order to improve teaching methods, it is necessary to study the applied field of general mathematics in depth.

In the educational and methodical literature one can find various interpretations of the concept of "financial mathematics". For example, G.I. Prosvetov understands this term as "any financial calculations aimed at achieving any goal". Its general characteristic is that "financial computing is an applied branch of mathematics that solves issues related to financial science, statistics and political economy by means of mathematical analysis".

The study of E.M. Chetyrkin, E.A. Fadeeva, and D.V. Ozherelyeva examined the forms of organization of educational methods through software and methodological support of courses on the study of elements of financial calculations in general, noncore.

According to the requirements of school programs, the value of mathematical education is its practical application in life, in studying related subjects, in continuation of education, which is measured by precise mathematical knowledge. In this regard, it is necessary to show pupils how to apply mathematical theory in applied activities. In other words, in order to improve teaching methods, it is necessary to study in depth the applied direction of general mathematical science.

Modern researchers C. Pournara, D. DeBock, Thomas Retzmann, Carly Sawatzki tried to update the definition of financial literacy by pointing out that communication and context are important constructive elements for understanding this kind of learning. The authors suggest ways to improve students' financial literacy by linking financial education and financial mathematics.

Analysis of the definitions suggests that financial literacy in teaching financial computation is a multifaceted concept. Scientists, depending on the goals, in their definitions emphasized the different aspects of financial education, not contrasting, but rather complementing each other. 


\section{Conclusion}

Proficiency training, which involves many opportunities to supplement the content of mathematics with financial computing, provides a good opportunity to prepare students for simple financial computing in terms of various payments, taxes, credit, insurance and other financial transactions. There is no point in explaining the need to study a school mathematics course, the possibilities of which are used to implement most of our plans, as at present financial and economic literacy of each person is one of the characteristics of his professional competence.

\section{Acknowledgement}

We are grateful to the International Kazakh-Turkish University named after A. Yasavi for supporting research.

\section{$7 \quad$ References}

[1] Lusardi, A., \& Mitchell, O. S. (2014). The economic importance of financial literacy: Theory and evidence. Journal of Economic Literature, 52(1), 5-44. https://doi.org/10.1257 ljel.52.1.5

[2] Lusardi, A., Mitchell, O. S., \& Curto, V. (2010). Financial literacy among the young. Journal of Consumer Affairs, 44(2), 358-380. https://doi.org/10.1111/j.1745-6606.2010.01 $\underline{173 . x}$

[3] Mandell, L. (2008). Financial literacy of high school students. In Handbook of Consumer Finance Research (pp. 163-183). Springer New York. https://doi.org/10.1007/978-0-387-7 $\underline{5734-6 \quad 10}$

[4] Xu, L., \& Zia, B. (2012). Financial Literacy around the World: An Overview of the Evidence with Practical Suggestions for the Way Forward. Policy Research Working Paper, (6107), 1-56. https://doi.org/10.3102/00346543067001043

[5] Atkinson, A., \& Messy, F.-A. (2012). Measuring financial literacy: Results of the oecd/international network on financial education (infe) pilot study. OECD Working Papers on Finance, Insurance and Private Pensions(15), 1. https://doi.org/10.1787/5k9csfs9 Ofr4-en

[6] Pazouki, T., Cornu, V., Sonnleitner, P., Schiltz, C., Fischbach, A., \& Martin, R. (2018). MaGrid: A language-neutral early mathematical training and learning application. International Journal of Emerging Technologies in Learning, 13(8), 4-18. https://doi.org/ 10.3991/ijet.v13i08.8271

[7] Sawatzki, C., \& Sullivan, P. (2018). Shopping for Shoes: Teaching Students to Apply and Interpret Mathematics in the Real World. International Journal of Science and Mathematics Education, 16(7), 1355-1373. https://doi.org/10.1007/s10763-017-9833-3

[8] Lopes, A. P., \& Soares, F. (2018). Perception and performance in a flipped Financial Mathematics classroom. International Journal of Management Education, 16(1), 105-113. https://doi.org/10.1016/j.ijme.2018.01.001

[9] Lusardi, A. (2019). Financial literacy and the need for financial education: evidence and implications. Swiss Journal of Economics and Statistics, 155(1). https://doi.org/10.1186/s4 $\underline{1937-019-0027-5}$ 
[10] N. Larracilla-Salazar., I.Y.Peña-Osorio., V.S. Molchanova. Education and Financial Inclusion. An Empirical Study in Studentsof Higher Education. European Journal of Contemporary Education, 2019, 8(4). 810-818. https://doi.org/10.13187/ejced.2019.4.810

[11] She, H. C., Stacey, K., \& Schmidt, W. H. (2018). Science and Mathematics Literacy: PISA for Better School Education. International Journal of Science and Mathematics Education, 16. https://doi.org/10.1007/s10763-018-9911-1

[12] Thomson, S., De Bortoli, L., \& Buckley, S. (2012). PISA 2012: How Australia measures up.

[13] Ramankulov, S. Z., Dosymov, E., Mintassova, A. S., \& Pattayev, A. M. (2019). Assessment of student creativity in teaching physics in a foreign language. European Journal of Contemporary Education, 8(3), 587-599. https://doi.org/10.13187/ejced.2019.3. $\underline{587}$

[14] Ramankulov, S., Usembaeva, I., Berdi, D., Omarov, B., Baimukhanbetov, B., \& Shektibayev, N. (2016). Formation of the creativity of students in the context of the education informatization. International Journal of Environmental and Science Education, 11(16), 9598-9613.

[15] Hopkins, S., \& O’Donovan, R. (2019). Using complex learning tasks to build procedural fluency and financial literacy for young people with intellectual disability. Mathematics Education Research Journal. https://doi.org/10.1007/s13394-019-00279-w

[16] Abylkassymova, A., Mukasheva, M., \& Zhumagulova, Z. (2018). Research into attitudes of subjects of education process in teaching programming. Opcion, 34(Special Issue 16), 171-183.

[17] Abylkasymova, A. E., Nurmukhamedova, Z. M., Nurbaeva, D. M., \& Zhumalieva, L. D. (2016). "The Turkish vector" influence on teaching the exact disciplines in modern educational system of Kazakhstan: On the example of teaching algebra and mathematics. Global Journal of Pure and Applied Mathematics, 12(4), 3481-3492.

[18] R.Mardanov \& A.Khasanova. (2014). Current issues of teaching mathematics in economic faculties of universities. Procedia - Social and Behavioral Sciences 152, $1062-1065$. https ://doi.org/10.1016/j.sbspro.2014.09.275

[19] OECD. (2014). PISA 2012 Results: Students and Money: Financial Literacy Skills for the 21st Century (Vol. 6; Tech. Rep.). https://doi.org/10.1787/9789264208094-4-en

[20] OECD. (2017). PISA 2015 results (Volume IV): students' financial literacy. Paris: PISA, OECD Publishi. https://doi.org/10.1787/9789264270282-en

[21] Stacey, K., \& Turner, R. (2015). Assessing mathematical literacy: The PISA experience. In Assessing Mathematical Literacy: The PISA Experience. https://doi.org/10.1007/978-3-319 $\underline{-10121-7}$

[22] Muñoz-Murillo, M., Álvarez-Franco, P. B., \& Restrepo-Tobón, D. A. (2020). The role of cognitive abilities on financial literacy: New experimental evidence. Journal of Behavioral and Experimental Economics, 84. https://doi.org/10.1016/j.socec.2019.101482

[23] Kopeyev, Z., Mubarakov, A., Kultan, J., Aimicheva, G., \& Tuyakov, Y. (2020). Using a Personalized Learning Style and Google Classroom Technology to Bridge the Knowledge Gap on Computer Science. International Journal of Emerging Technologies in Learning (IJET), 15(02), 218. https://doi.org/10.3991/ijet.v15i02.11602

[24] Mubarakov, A. M., Yerkisheva, Zh.S. (2018). Consideration of the basics of financial accounting in the context of profile education in the system of general education.

[25] Savelsbergh, E. R., Prins, G. T., Rietbergen, C., Fechner, S., Vaessen, B. E., Draijer, J. M., \& Bakker, A. (2016). Effects of innovative science and mathematics teaching on student attitudes and achievement: A meta-analytic study. Educational Research Review, 19, 158172. https://doi.org/10.1016/j.edurev.2016.07.003 


\section{Authors}

Alma Abylkassymova is Professor, Head of the Department of Mathematics, Physics and Informatics Teaching Methods, Institute of Mathematics, Physics and Informatics, Abai Kazakh National Pedagogical University. aabylkassymova@mail.ru

Akhan Mubarakov is Professor, Department of Computer science, L.N. Gumilyov Eurasian National University. akan-mubarak@mail.ru

Zhazira Yerkisheva is Ph.D student, Department of Mathematics, Faculty of the Natural Science, Khoja Akhmet Yassawi International Kazakh-Turkish University. zhazira.erkisheva@ayu.edu.kz

Zhannur Turganbayeva is Ph.D student, Department of Mathematics, Faculty of the Natural Science, Khoja Akhmet Yassawi International Kazakh-Turkish University. zhannur.turganbayeva@ayu.edu.kz

Zhomart Baysalov - Professor, Kyrgyz State University I. Arabaev bamart@mail.ru

Article submitted 2020-04-03. Resubmitted 2020-05-17. Final acceptance 2020-05-18. Final version published as submitted by the authors. 